\title{
Coordinating Health and Industrial Policy in South Africa; A Case Study of the Vaccine Public-Private Partnership
}

\section{David R Walwyn* and Adolph T Nkolele}

Graduate School of Technology Management, University of Pretoria, South Africa

*Corresponding author, email: david.walwyn@up.ac.za

Established in 2003 as a Public-Private Partnership (PPP) covering vaccine research and development, manufacturing and supply, the Biovac Institute has grown from an initial base of 24 staff and a revenue of R188 million to an organisation of 250 people and an annual revenue of R1.8 billion (as of January 2018). The institute earns a premium on the procurement cost of a broad range of vaccines required by the National Department of Health $(\mathrm{NDoH})$, the net value of which reached R1.14 billion over the period 2010-2014 and was used to finance the institute's operations, including vaccine distribution and quality control. In this study, we have evaluated the value-for-money of the partnership within a context of tension between health and industrial policy. According to the respondents in the qualitative survey, its principal benefit has been the uninterrupted supply of vaccine and the ability to respond quickly to vaccine shortages. The main disadvantages appear to have been the slow establishment of vaccine manufacturing, and initially a limited ability to negotiate highly competitive vaccine prices. Overall, it is concluded that the institute has delivered value-for-money and met the objectives of both industrial and health policy. However, the experience appears not to have convinced the $\mathrm{NDoH}$ of the value of such initiatives.

Keywords: Vaccines, Public Private Partnership, Cost-Benefit Analysis, Local Manufacture, Health Security

\section{Introduction}

Vaccines are a cornerstone of public health policy, indispensable to the prevention of childhood illness and the reduction of mortality arising from a broad range of infectious diseases, including diphtheria, tetanus, pertussis, hepatitis $B$, haemophilus influenza virus and rotavirus. They provide universal prophylaxis at a fraction of the cost that would otherwise be incurred through the treatment of an infectious disease outbreak. Every dollar invested in immunisation generates a return of $\$ 16$ in the form of savings to public healthcare costs and increases in economic productivity. ${ }^{1,2}$ As a consequence, the World Health Organisation, through the activities of the Global Vaccine Action Plan, is working to raise levels of vaccination coverage to at least $90 \%$ by 2020 , especially in the critical areas of diphtheriatetanus-pertussis (DTP), Haemophilus influenzae type b (Hib), Hepatitis B, measles and polio. ${ }^{3}$

South Africa has an extensive childhood vaccination programme, known as the Expanded Program on Immunisation (EPI), which forms part of the broader health strategy of the National Department of Health (NDoH). Implementation of the EPI requires the procurement of about 46 million doses annually of vaccine at a cost of about R1.5 billion per annum (2015 values), an amount which has grown in nominal and real terms since 1997 at rates of $26 \%$ and $18 \%$ respectively. Vaccines now account for $1 \%$ of South Africa's total public health budget and are administered to at least 1 to 2 million children per year. The expansion of the programme has led the $\mathrm{NDoH}$ to claim immunisation as a major achievement in its overall efforts to reduce childhood mortality. ${ }^{4}$

Prior to 2003, vaccine procurement was an internal function of the $\mathrm{NDoH}$; the department issued tenders on behalf of the provinces and secured the necessary supply from successful bidders. However, since 2004 vaccine procurement and distribution has been undertaken by a public private partnership (PPP) referred to as the Biovac Institute (BI), which was established as a means of incentivising investment in vaccine manufacture through the leveraging of public procurement. ${ }^{5}$

Vaccine procurement illustrates very clearly the tension between various forms of policy in government, and in this case the tension between health policy, trade policy, industrial policy and innovation policy. Whilst complete policy coherence is almost impossible to achieve, and probably also undesirable due to the bureaucratic infrastructure which would be required, there are strong arguments in support of the use by the state of its procurement process to leverage local manufacture, and hence achievet alignment between health and industrial policy. ${ }^{6-8}$

Such arguments are further supported by the critical nature of essential medicines for which any interruption in supply may have serious public health consequences. Although the achievement of national (defence) security or food security is accepted as a valid public policy objective, there is little mention of health security. Ensuring the supply though the local manufacture of 
essential medicines, in order to avoid shortages seems to be an obvious and necessary part of a public health strategy. ${ }^{9}$

BI was developed as a way of ensuring at a partial level, at least, of vaccine security. It was not the first such initiative in South Africa. As early as the 1970s, the State Vaccine Institute was established in Cape Town for the manufacture of a TB vaccine (BCG). This was followed by the commissioning of the South African Vaccine Producers in Johannesburg. However, by the 1990s, both facilities had been criticised by the WHO as failing to meet global standards of manufacturing and being in urgent need of new equipment and technology. The concept of the BI-PPP was formulated to attract private sector investment and management skills in order to supply EPI vaccines.

In this article, the results of a cost-benefit analysis of the BI-PPP are presented. The first section covers the general theoretical framework for PPPs; this is followed by an overview of South Africa's immunisation programme and the formation of the BlPPP. Details of the research questions and methodology are then presented, leading to the results and finally a detailed discussion of the implications thereof. The article concludes with an overall comment on the value of the PPP and how similar projects within the general area of public health could be addressed in the future.

\section{Overview of Public Private Partnerships}

\section{General Theory}

PPPs cover a broad range of intersectoral initiatives in which the two partners share varying levels of risk, benefit, resources and responsibilities. A useful framework for understanding this diversity has been described by Brinkerhoff and Brinkerhoff, ${ }^{10}$ who define the two dimensions of mutuality and organisational identity through which PPPs can be classified. The former refers to the extent to which the partners share control, decisionmaking and responsibility, whereas the latter covers the unique competencies, capabilities, markets and comparative advantages. An ideal PPP is considered as a partnership in which mutuality is high but organisational identities are retained throughout the project. This form of PPP can be easily separated from conventional contracting (high organisational identity, low mutuality), extension of competence (low organisational identity, low mutuality) and eventual absorption (low organisational identity, high mutuality).

A key success factor for PPPs is the effective allocation of risk, which includes the initial identification of project risk factors followed by the allocation of these factors to that party which is best able to manage them, ${ }^{11,12}$ a difficult process which can result in under-identification or misallocation, with the result that projects fail to meet targets relating to scope, time and budget. ${ }^{11}$ Another difficulty of the PPP relationship, indeed of many contractual arrangements, is that of information asymmetry, in which one party is more privileged in terms of important data and which can be the source of conflict, leading to the eventual breakdown of the partnership.

\section{Health and Industrial Policy}

Although South Africa's Constitution guarantees every citizen access to health services (Section 27 of the Bill of Rights), the extent or quality of this access is determined by a patient's capacity to pay, leading to large differences in health access between different income groups. ${ }^{13}$ Reducing such disparities has been a core focus of health policy since 1994, which has attempted to expand the coverage of the public health system without increasing costs to the patient. Measures to contain health costs and particularly to control the procurement costs of essential medicines have been integral to the access issue. ${ }^{14}$

This aspect of health policy has placed it in direct conflict with industrial, and to some extent procurement, policy since the procurement process does allow for factors other than price to be considered. ${ }^{15}$ For instance, the Preferential Procurement Policy Framework Act (Act 5 of 2000), allows for an 80:20 (or $90: 10$ ) preference points system to be applied in the adjudication of public tenders where the $20 \%$ or $10 \%$ weighting is allocated based on factors such as local content, black economic empowerment, job creation and community development.

Similarly, the Preferential Procurement Regulations, 2017, issued in terms of the Preferential Procurement Policy Framework Act (Act 5 of 2000), makes provision for the Department of Trade and Industry to designate sectors as sole suppliers of goods, where the latter are considered to be critical components of national development and industrial policy. The regulations allow for the procurement of goods only where these have been locally manufactured, with a stipulated minimum threshold for local production and content. Examples of such designated sectors in South Africa include buses, power lines, certain pharmaceuticals and solar photovoltaic components. The antiretrovirals tender, worth an estimated R3.5 billion per annum, allocated 70\% to local manufacturers following the designation of the sector in 2012.16,17 This designation has been a major factor in the revitalisation of the local pharmaceutical industry at a time when it was under pressure from Indian and Chinese imports.

\section{Public Private Partnerships in South Africa}

South Africa followed a global trend in the popularity of PPPs by establishing a more formal PPP structure within National Treasury in 1999. Although there were PPPs prior to this date, these arrangements did not follow a standardised process or receive formal recognition as PPPs within the treasury. Following the launch of the PPP unit in 1999, National Treasury (of South Africa) developed a standardised procedure for such entities. It defined a PPP as a "contract between a government institution and a private party, where the private party performs an institutional function and/or uses state property in terms of output specifications; substantial project risk (financial, technical, operational) is transferred to the private party; and the private party benefits through unitary payments from government budgets and/or user fees".18

The documentation further proceeded to define the important qualifying factors for PPPs, which include risk transfer to the 
private sector (does the PPP result in the transfer of financial or project risk which may be incurred including the risk of time overruns, revenue projections and operational costs?), affordability (is the project within existing budget constraints?) and value for money (will the PPP be less costly than the stateowned alternative?). All PPPs were required to follow an approval process in which these questions were formally answered as part of the rationale for the partnership. The requirement of risk transfer is perhaps unrealistic considering that the state as an actor in a PPP is never freed from risk; given the asymmetries which arise, risk remains an ongoing and visceral property of a PPP which can never be entirely transferred or avoided.

\section{Formation of the Biovac Institute}

BI was formed in 2003 through a strategic equity partnership with the Biovac Consortium (Pty) Ltd, where the latter was a private company comprised of a number of shareholders, namely Biovac Holdings (62.5\%), Heber Biotec (15\%), VaxIntel (15\%) and the Disability Employment Concern Trust (7.5\%). The Biovac Consortium held a controlling share in $\mathrm{BI}$ (52.5\%), with the remainder being held by the $\mathrm{NDoH}$. Importantly, the latter shareholding has subsequently been transferred to the Department of Science and Technology, an issue which is discussed later.

The partnership was initiated after the NDoH acknowledged the deterioration in South Africa's vaccine production assets and hence the need to access external competency in this critical area. It was apparent from the earliest stages of the PPP that its objective was not to address issues of vaccine supply chain management, which was already being outsourced to the suppliers of vaccines within the immunisation programme and with which there were no immediate concerns given that shortages or supply failures to the various clinics and depots had not yet occurred. Neither were there issues of tendering and contracting; the $\mathrm{NDoH}$ was already implementing very successfully other procurement processes for the purchase of essential medicines, including the antiretroviral programme. Instead, the PPP was motivated by the need to maintain security of supply through local manufacturing, a tradition which had its origins in earlier projects and had resulted in the manufacturing facilities for a number of vaccines, including polio and Bacillus Calmette-Guérin (BCG), where the latter is used to prevent tuberculosis. This central rationale and its associated objectives were captured in the Shareholders Agreement, as shown in Table 1.

The original agreements, as signed in 2004, consisted of a Supply Agreement, the Shareholders Agreement, the Subscription Agreement and the Strategic Equity Partner Undertakings. The agreements initially covered the period 2004-2010 but were subsequently renewed to the end of 2016. The Supply Agreement dealt with the $\mathrm{NDoH}$ outsourcing of procurement, central level storage, and distribution of vaccines to nine provincial vaccine storage depots. ${ }^{20}$ As defined by this agreement, $\mathrm{Bl}$ charged the NDoH both the purchase cost of vaccines and the price premium where the latter varied between $10 \%$ to $20 \%$ and covered all aspects of the procurement and distribution, plus the capital expenditure/research and development necessary to establish vaccine manufacture. ${ }^{20,21}$ Such an arrangement can best be described (within the World Bank typology) as a private ownership/private finance initiative in which the private partner owned a controlling share of the assets and in principle secured investment funding from private entities. In practice, the required capital funds were sourced through public entities including the Industrial Development Corporation and the Technology Innovation Agency, although some of these funds were made available in the form of loans and should be treated as private funding.

Table 1. BI-PPP objectives as listed in the Shareholders Agreement

\begin{tabular}{|l|l|}
\hline Category & Objective \\
\hline $\begin{array}{l}\text { Vaccine Production } \\
\text { (Capacity) }\end{array}$ & $\begin{array}{l}\text { Ensure a domestic capacity in vaccine production which will enable the South African health authorities to respond } \\
\text { to disease outbreak emergencies }\end{array}$ \\
\hline Vaccine Production (Quality) & $\begin{array}{l}\text { Establish an economically viable vaccine producer applying the principles of current good manufacturing practice } \\
\text { (cGMP) }\end{array}$ \\
\hline Vaccine Production (Skills) & $\begin{array}{l}\text { Develop and retain local vaccine production related skills and ensure the continued development of biotechnology } \\
\text { and related skills }\end{array}$ \\
\hline Research and Development & $\begin{array}{l}\text { Establish a strong research and development (R\&D) capability focused on the development of locally relevant } \\
\text { vaccines }\end{array}$ \\
\hline Markets (Exports) & $\begin{array}{l}\text { Create a competitive platform from which a domestic producer of human vaccines and related medical } \\
\text { biotechnology products can compete with other markets }\end{array}$ \\
\hline Markets (General) & Ensure that any development in this sector in South Africa opens access to other markets as potential customers \\
\hline $\begin{array}{l}\text { Black Economic } \\
\text { Empowerment (BEE) }\end{array}$ & Promote BEE and the identification of a BEE partner to participate through a shareholding in BI \\
\hline
\end{tabular}

Source: Naidoo ${ }^{19}$

Table 2. Values for exchange rates and normalisation factors (2010)

\begin{tabular}{|l|l|l|l|l|l|l|}
\hline Year & $\mathbf{2 0 1 0}$ & $\mathbf{2 0 1 1}$ & $\mathbf{2 0 1 2}$ & $\mathbf{2 0 1 3}$ & $\mathbf{2 0 1 4}$ \\
\hline Currency conversion (South Africa Rand to US dollar) & 7.638 & 7.562 & 8.553 & 10.037 \\
\hline Normalisation factor (conversation to 2010 Rands) & 1.000 & 0.938 & 0.889 & 0.838 \\
\hline
\end{tabular}


Before the five agreements, including the Supply Agreement, could be signed by the PPP partners, the Transaction Adviser was required, in accordance with the National Treasury Regulations, to undertake a value-for-money study and determine whether the partnership would indeed result in a positive public outcome without additional cost or risk. This study concluded that "Government will be able to retain and build local vaccine manufacturing capacity, allow the transfer of key vaccine $R \& D$ and manufacturing skills to South Africa, and build a sustainable, export oriented industry which the same time can support local initiatives such as the search for an effective HIV vaccine".22 Furthermore, the analysis confirmed that the partnership would result in a significant transfer of risk to the private sector. The objective of this research has been to establish, with hindsight, whether these assessments were in fact accurate and whether the PPP did generate a positive value-for-money over the period 2010-2016.

\section{Methodology}

The general methodological approach to this study has been based on a concurrent mixed methods approach. In an initial quantitative study, data for prices and product volumes were extracted from secondary data sources (mainly financial statements for the $\mathrm{BI}$ ) and used to calculate the economic cost of the BI-PPP. Simultaneously a qualitative study was undertaken in which a number of key stakeholders in the PPP were identified and then interviewed on their perceptions of the value of the PPP using a semi-structured questionnaire. Such approaches to the evaluation of public health interventions have become widely used. ${ }^{2,23}$ Each study is now covered in more detail.

\section{Economic Evaluation of Immunisation Programmes}

Specific approaches to the evaluation of vaccination programmes have been covered in the publication on "Guidelines to Economic Evaluations for Immunisation Programmes".24 The publication covers the processes for economic evaluation with the aim being to present clear, concise, practical and high-quality guidance for performing and presenting the results of economic evaluations. ${ }^{24}$ Four types of economic evaluation techniques are recommended, namely cost-minimization analysis (CMA), costeffectiveness analysis (CEA), cost-utility analysis (CUA) and costbenefit analysis (CBA). ${ }^{25}$ Almost all the evaluation techniques estimate costs in a similar style, but measure outcomes or consequences differently. ${ }^{25}$ The different ways of measuring benefit reflect varying levels of the balance between the potential impact of a study and the practicality of its completion. Although cost minimisation assessments are relatively easy to undertake, they have little benefit in the strategic management of public health. Similarly, long-term social benefits are difficult to assess, but have the greatest importance in terms of influence on public health debates.

For the purposes of this discussion, the objectives as listed in Table 1 have been used as the basis for the performance evaluation. However, the list in the table has two obvious omissions, namely timelines and costs. As a result, this study has chosen to benchmark the prices paid by the NDoH against those prices negotiated and published by the Pan American Health Organisation (PAHO) as a means of assessing the cost aspects of the economic evaluation. Although the prices are not strictly comparable (see later), $\mathrm{PAHO}$ prices provide a consistent basis for the comparison of South African vs. international prices. Using this basis, the main research questions of the study now became:

- What were the PAHO and South African prices for vaccines over the reference period?

- What was the price premium paid by the NDoH?

- How were these funds allocated and spent by BI?

- What was the value-for-money for the public sector as a consequence of the partnership?

The study used the univariate and bivariate methods for graphical display and to compare results. International prices were converted to South African Rand (ZAR) values using the average exchange rates in any particular year, adjusted for purchasing power parity, thereby ensuring the validity of the comparison, as shown in Table 2.

\section{Qualitative Study}

Qualitative studies are useful in business research because they provide clarity on key issues which is generally not accessible through quantitative data. ${ }^{26}$ In this work, a qualitative phase was considered to be important as a means of establishing the phenomenological aspects of the PPP, especially to its key stakeholders, such as NDoH and National Treasury. In this respect, qualitative data can provide a more informed and detailed understanding of initiatives such as BI-PPP, thereby generating new ideas and suggestions for improvements. ${ }^{27}$

The qualitative component of this study was designed to address the final research question on perceived value-formoney. A purposive sampling strategy was followed through which key stakeholders in the BI-PPP were identified, including representatives from $\mathrm{Bl}$, National Treasury, $\mathrm{NDoH}$, provincial departments of health, the Technology Innovation Agency, the Industrial Development Corporation, the Department of Science and Technology and the Department of Trade and Industry. Once potential respondents had been listed (nine altogether), an interview request was sent through via email, together with a prior informed consent form and a provisional set of questions. The latter were prepared in the form of a semistructured questionnaire in order to re-assure the respondents that the study was bona fide, but also to allow for more general elaboration and discussion where necessary or required. ${ }^{28}$

Only five of the sample (55\%) agreed to proceed with the interview. It is noted that different modes of interviews were used, including a Skype video call, face-to-face interview, and telephone call. In all cases the conversations were recorded and transcribed. Content analysis was undertaken using ATLASti. In the first case, common themes between the respondents were established and then the transcribed text was annotated according to each theme. This approach facilitated an 
understanding of the responses and the development of the discursive content in the analysis.

\section{Results}

$\mathrm{Bl}$ is located in Cape Town, South Africa. The institute has a range of facilities including the Cold Room Warehouse, Quality Control Room, Production, and R\&D Pilot Plant. As of the end of 2017, it employed 250 employees and distributed about 12 million vaccine vials, equivalent to 46 million doses, per year through its Johannesburg and Cape Town distribution centres. The institute procures a broad range of vaccines on behalf of the $\mathrm{NDoH}$, as has already been noted. As of the end of 2014, the largest value vaccines were Pneumococcal conjugate vaccine (PCV; 38\%), followed by Pentaxim (35\%) and finally the rotavirus vaccine (Rota; 10\%) as shown in Figure 1.

It is apparent that BI has become a sizeable organisation. In 2004, at the time of its initial establishment, the annual expenditure on public sector vaccines was $\$ 37.5$ million. ${ }^{29}$ By 2012 , this value had grown to $\$ 160$ million, an increase of over $400 \%$ in real terms,

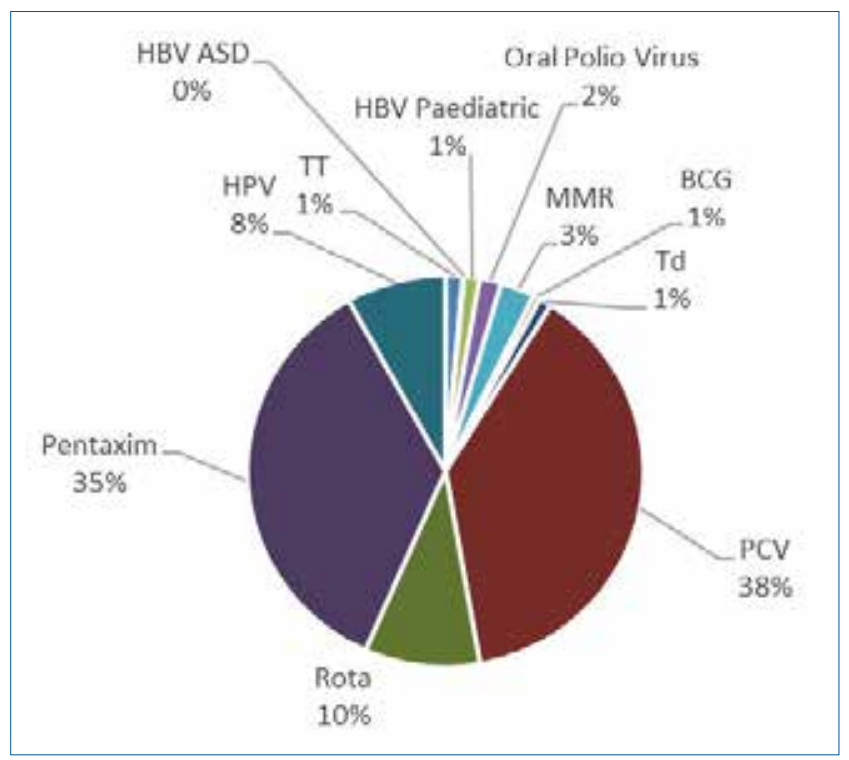

Figure 1. Vaccine components by revenue contribution primarily as a consequence of the inclusion of several additional vaccines to the EPI (see Figure 2). Since 2012, the total revenues have declined in dollar terms following the rapid depreciation of the South African Rand relative to the dollar.

The initial projections of the Transaction Adviser did not come even close to predicting this steep increase in revenue and the required level of human resources/capital investment were significantly under-estimated, with deep implications for the ability of the BI-PPP to deliver on its objectives. It is perhaps the most profound outcome of this PPP project, namely that the partnership between two such disparate parties is challenging under the best of circumstances, but even more complex within a high-technology and rapidly changing environment.

\section{Vaccine Purchase Prices}

The cost-benefit analysis for BI-PPP has been conducted at two levels; firstly the ability of the institute to access globally competitive prices has been evaluated by the comparison of the $\mathrm{BI}$ cost prices against the PAHO prices. Secondly, the monetary value of the premium has been assessed relative to the institute's contribution to the vaccine supply chain and its progress on the PPP objectives.

As already noted, direct cost comparisons between $\mathrm{BI}$ and PAHO prices can be misleading due to the variations in the components included in the base price. For instance, the standard component is the manufacturer's ex-factory price, but the supplied cost may or may not include freight costs, import tariffs, port fees, customs clearance fees, taxes, mark-ups collected by brokers, distribution costs, overhead costs and procurement costs. The estimated price components can add $30-45 \%$ to the original cost from the time the vaccines get dispensed. ${ }^{30}$ Furthermore, it is important but difficult to attach a common standard on quality and reliability, including issues such as stock-outs, delivery of damaged goods, safety of vaccines and reliability. Greater care in the delivery chain inevitably adds cost, and a direct comparison of vaccine prices is less meaningful unless the quality criteria are applied consistently.

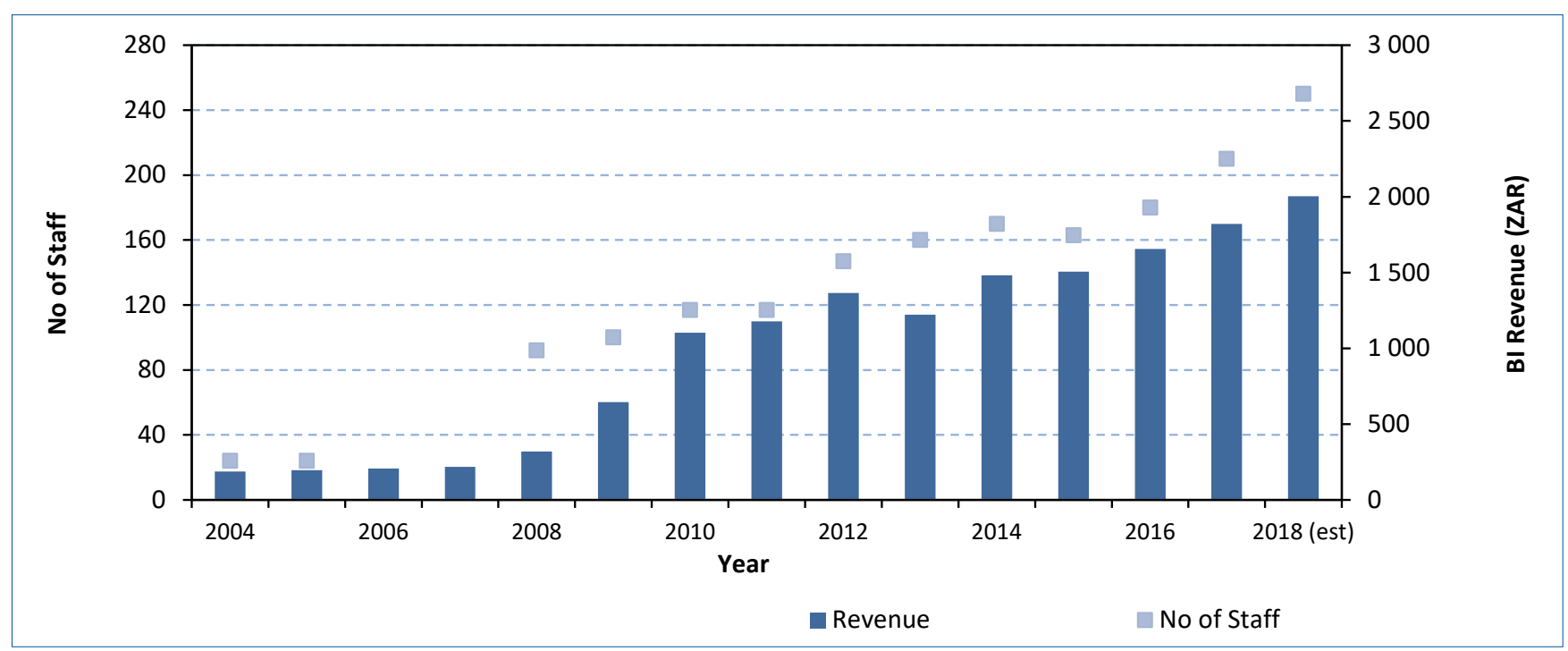

Figure 2. Growth of the Biovac Institute (2004 to 2018) 
Table 3. Total additional expense BI via PAHO excluding premium (US\$ million)

\begin{tabular}{|c|c|c|c|c|c|c|}
\hline Vaccine Type & 2010 & 2011 & 2012 & 2013 & 2014 & Total \\
\hline TT & N/A & N/A & N/A & N/A & N/A & N/A \\
\hline HBV ASD & 1.0 & 1.2 & 1.5 & 1.6 & 0.6 & 5.9 \\
\hline HBV Paediatric & 5.0 & 8.5 & 9.5 & 9.6 & 2.1 & 34.7 \\
\hline OPV & 0.1 & 2.7 & 10.1 & 7.8 & 5.1 & 25.7 \\
\hline Measles/MMR & 7.7 & 14.7 & 25.6 & 26.6 & 32.9 & 107.5 \\
\hline BCG & -0.4 & 1.1 & 1.8 & 4.7 & -0.8 & 6.4 \\
\hline Td & 9.0 & 12.9 & 15.0 & 19.2 & 10.2 & 66.3 \\
\hline PCV & 110.4 & 236.6 & 210.1 & 87.9 & -10.0 & 635.0 \\
\hline Rota & -4.7 & 14.5 & 27.0 & 37.0 & -15.2 & 58.7 \\
\hline Pentavalent & 138.7 & 169.8 & 186.0 & 180.9 & -18.9 & 656.5 \\
\hline HPV & 0.0 & 0.0 & 0.0 & 0.0 & -2.8 & -2.8 \\
\hline Total & 266.9 & 462.0 & 486.6 & 375.3 & 3.2 & $1,594.1$ \\
\hline
\end{tabular}

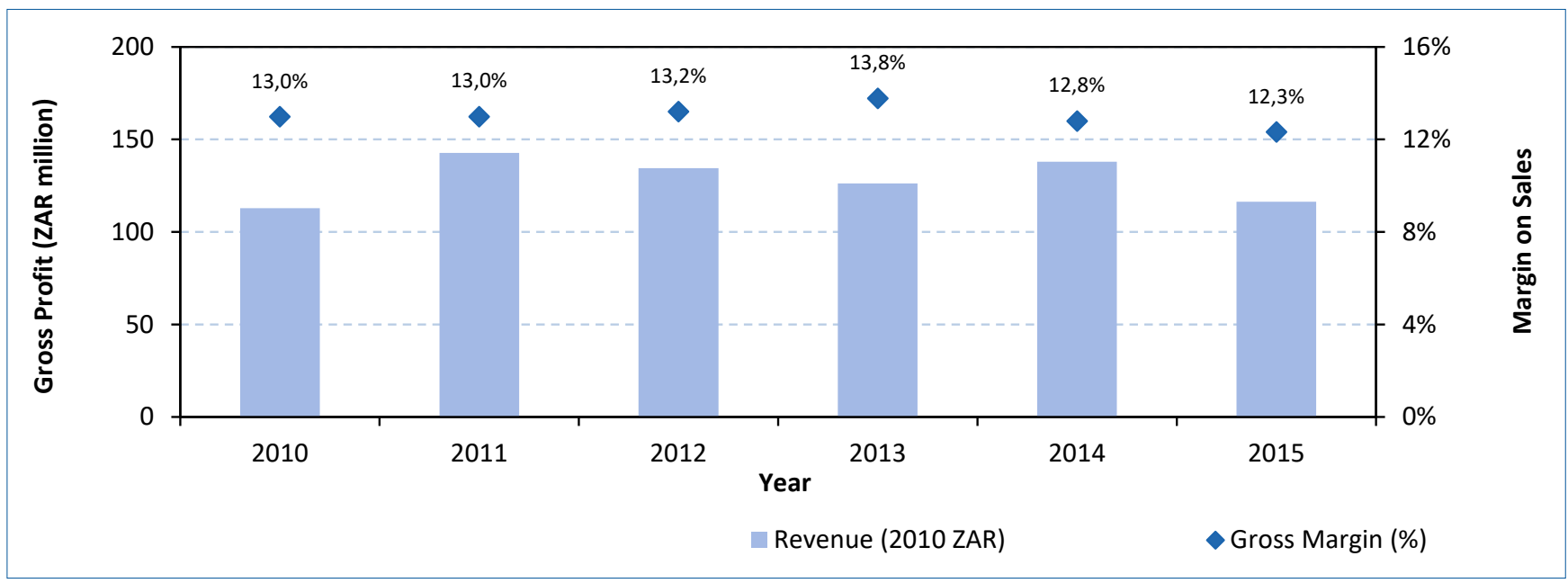

Figure 3. Gross profit and margin over the evaluation period

Based on the values for the number of doses procured annually on behalf of the $\mathrm{NDoH}$ by $\mathrm{BI}$, the total value of the additional expense per vaccine which has been incurred as a consequence of independent procurement can be calculated and is shown in Table 3. Over the period 2010 to 2014, the BI-negotiated prices were about R1.6 billion higher for the total portfolio vs. PAHO. However, $85 \%$ of the price difference can be found in the two newly introduced products of the pentavalent (Pentaxim) and PCV, and in the early years of the study immediately following their introduction. By 2014, the differences on these products were almost negligible relative to the PAHO price, and the two portfolios has reached equivalence, as shown in Table 3.

Based on this trend, it can be argued that BI has been successful in containing the cost of procurement for the EPI vaccines, and that this competence has been strengthened over the period of this study. In other words, procurement prices have not been inflated, either as a means of securing higher levels of funding from the $\mathrm{NDoH}$, given that this funding is charged as a percentage of the procurement value, or as a consequence of a weakened bargaining position (relative to the NDoH).

\section{Value Addition Services and Premium}

The second aspect of the cost-benefit ratio is now considered (value for money arising from Bl's contribution to the overall vaccine value chain). The analysis initially confirmed the quantity of the premium charged to the NDoH as permitted within the PPP Supply Agreement. This premium is negotiated on a productspecific basis by $\mathrm{BI}$ and varies from $10 \%$ to $20 \%$. It is intended to cover all aspects from manufacture (if applicable) to distribution of the packaged/labelled product to the health depots, as may be applicable to the individual products.

Figure 3 illustrates the gross margin on sales, essentially equivalent to the premium, received by the institute between 2010 and 2015. The margin averaged at about 13\%, corresponding to a total value of $\$ 85.7$ million over the period of the evaluation or about $\$ 17$ million per year. It is noted that there are small differences, mostly the consequence of exchange rate fluctuations, between the total margin, as reported in the Bl's Annual Financial Statements, and the total premiums, as calculated from the reported volume of sales and the agreed premium for each product.

In addressing the question as to whether the margins represent a fair deal to both parties of the PPP, it is necessary to consider 
the added value for each product and the typical cost that such a contribution would attract in the overall calculation of the final cost. Actual values for costs as a function of value addition are not available and will generally vary widely within the industry based on geographic location and type/scale of product. In this study, a set of rough guidelines have been used as shown in Table 4.

Table 4. Guidelines for contribution to vaccine price per activity

\begin{tabular}{|l|c|}
\hline Activity & $\begin{array}{c}\text { Contribution to Price (\% of } \\
\text { total price) }\end{array}$ \\
\hline Packaging and labelling & $5 \%$ \\
\hline Procurement & $1 \%$ \\
\hline Contract management & $1 \%$ \\
\hline Financial management & $2 \%$ \\
\hline Cold chain warehousing & $5 \%$ \\
\hline Warehousing & $3 \%$ \\
\hline Logistics (distribution) & $5 \%$ \\
\hline
\end{tabular}

Table 5 indicates the premium that was charged and required activities that took place on the vaccine before it could be distributed. Some vaccines arrive as finished products and are ready for distribution after minimal quality assurance, whilst other vaccines arrive incomplete and require filling/packaging. The premiums are calculated based on the required activities and the total volumes, where the latter are important given that there are significant economies of scale. The values have been used to calculate estimated costs per product, also shown in Table 5. On the basis of these values, it can be concluded that there is good agreement between the actual costs and Bl's value addition to the product. Indeed, if the calculated values are inserted into the calculation for the total premium paid over the reference period, the comparable amounts are R945 million (calculated) vs. R764 million (actual).

\section{Qualitative Assessment of the Institute by the Interviewees}

As noted in the methodology section, a number of interviews were held with key stakeholders in order to obtain qualitative feedback on Bl's performance over the evaluation period, and more generally its contribution to vaccine manufacture and supply within South Africa. The results of these discussions are now presented, covering both the respondents' perceptions of the cost-benefit ratio, and progress in respect of establishing manufacturing infrastructure and a research and development portfolio.

\section{Value for Money}

There was a common perception that the PPP could be described as a success because there were no vaccine shortages around the country and supply security had been assured. Most respondents indicated that the PPP delivered value for money to the public of South Africa. Furthermore, it was noted that there had been no interruption in the supply of vaccines to any location in the country.
Table 5. Premiums charged and activity per vaccine

\begin{tabular}{|c|c|c|c|}
\hline Vaccine Type & Activity & $\begin{array}{l}\text { Agreed } \\
\text { Premium }\end{array}$ & $\begin{array}{l}\text { Calculated } \\
\text { Premium }\end{array}$ \\
\hline TT & Cold chain distribution & $15 \%$ & $14 \%$ \\
\hline $\begin{array}{l}\text { HBV (ASD and } \\
\text { Paediatric) }\end{array}$ & $\begin{array}{l}\text { Packaging, labelling, and } \\
\text { distribution }\end{array}$ & $20 \%$ & $17 \%$ \\
\hline OPV & Cold chain distribution & $15 \%$ & $14 \%$ \\
\hline Measles & Cold chain distribution & $15 \%$ & $14 \%$ \\
\hline BCG & $\begin{array}{l}\text { Packaging, labelling and } \\
\text { distribution }\end{array}$ & $20 \%$ & $17 \%$ \\
\hline $\mathrm{Td}$ & Cold chain distribution & $15 \%$ & $14 \%$ \\
\hline PCV & $\begin{array}{l}\text { Packaging, labelling and } \\
\text { distribution }\end{array}$ & $10 \%$ & $17 \%$ \\
\hline Rota & Cold chain distribution & $10 \%$ & $14 \%$ \\
\hline Pentaxim & Distribution & $15 \%$ & $12 \%$ \\
\hline HPV & Distribution & $15 \%$ & $12 \%$ \\
\hline
\end{tabular}

"...the vaccine was distributed on a budget, on time and under appropriate conditions, which hadn't been happening before 2003. Vaccine distribution before the PPP was not reliably sustainable."

"...the distribution is sufficient (satisfactory) and works well. Also look at the availability of vaccines in South Africa, there have been one or two hiccups (shortages or challenges) (only) ... we (the country) needs to have (vaccine) supply security..."

The importance of a private sector partner in this respect was noted.

"...if government is unable to distribute no matter what its attempts are... and, the private sector does distribute, that is value for money. However, in this particular case government could not do what we ended up paying the private sector to do. So there's no question about value for money. The government could not do it (supply and manufacturing). Only the private party could do it..."

"...Being a one stop shop to some extent I think has provided value because we are dealing with about eight different suppliers, whereas the Department of Health and just government, in general, has to deal with only one supplier being BIOVAC."

The value of the supply reliability was considered to be 'beyond estimation', given that even if the overall price was higher than it could have been with in-house procurement and distribution, the fact that no child had died as a consequence of not receiving an EPI vaccine was an invaluable contribution.

However, not all participants agreed to the statement on valuefor-money, with one respondent noting that:

"...South Africa pays too much for vaccines and... it is a victim of the fact that you have only a couple of suppliers"

This view has been previously stated in the literature, ${ }^{31}$ and was the main reason that the study considered the comparison between PAHO and BI prices. As noted earlier, although this 
comment was a valid criticism of the early years covering the introduction of the new vaccines (rotavirus and PCV), by 2014 the local prices in South Africa were highly competitive.

\section{Investment in Capital Equipment and Research}

During the interviews, the respondents were informed that between 2010 and 2014, BI had received almost R764 million from the premium charged to the NDoH according to the PPP agreements, and that these funds were being used to support the establishment of local vaccine manufacture, including the construction of the required infrastructure (clean rooms, filling lines, etc.) and a R\&D pipeline. The respondents were questioned on their perception of the institute's progress towards the achievement of the Strategic Equity Partner undertakings, as outlined earlier. In general, the respondents expressed frustration at the slow progress, noting that as of the beginning of 2015, the PPP had entered its 12th year and that local manufacturing (other than packaging and labelling) was still to take place. BI explained its strategy, and hence the slow progress, as follows:

"They (funds received) were applied for establishing the capability to help pay for the facilities, (and) to develop the staff. This is all in preparation for the (future) benefits."

"...packaging is maybe the smaller contribution but we are going to filling, and we are going to formulation slowly ..."

"Blcurrently havefour signed technology transferagreements. The Pfizer agreement was supposed to be concluded by October 2015. Once all these deals and agreement are secured, BIOVAC would have had seven EPI vaccines covered."

In other words, BI has pursued a phased strategy with backwards integration from the least technology intensive steps. However, it appears that the stakeholders have little understanding of this strategy or the progress that has been made, including the development of the packaging and labelling facility. It appears that BI's initial strategy had been to invest in human resource development as a way of preparing the institute for its future manufacturing activities. According to a Frost \& Sullivan report, ${ }^{32}$ commissioned by the Biovac Consortium, about 3720 hours were spent on internal training at the BI facility in 2015 and in the same year a total of R2.97 million was spent on external training, with much of this training being based on technical skills development.

Similarly, many of the respondents indicated that they are unaware of any benefits from the R\&D efforts or even the details of the programme. This view indicates poor communication between the institute and its stakeholders given that there had been some significant achievements. For instance, BI has developed technology for a conjugate vaccine which had recently been licensed to two international companies. The latter companies have successfully commercialised the antigen and achieved WHO prequalification status for their pentavalent vaccine. $\mathrm{BI}$ is currently receiving income through licensing fees for the technology. This achievement, which is considered to be a milestone for the institute in its efforts to become an international vaccine company, has not been well publicised.

\section{Discussion}

The formation and operation of the BI-PPP have been unique within the South African context. Firstly, as far as the authors are aware, it is the only private ownership/private finance initiative in the country. Secondly it is effectively a demand-side instrument to build manufacturing capacity in a critical area for the public health sector. The uniqueness of the demand-side nature of the PPP has to be appreciated within the country's overall policy context. Following the trade negotiations in the 1990s, the country adopted an economic policy framework which opened its borders to international trade and competition whilst simultaneously providing more extensive supply-side support for its manufacturing sector. ${ }^{33}$ Recent work on the extant policy mix has shown that supply-side instruments account for more than $98 \%$ of the total funding vs. $80 \%$ for Canada and $60 \%$ for India. ${ }^{34}$ Indeed, it appears that $\mathrm{BI}$ is one of only three demandside instruments, alongside the Renewable Energy Independent Power Producers Procurement Programme in the energy sector and the Automotive Production and Development Programme in the automobile sector.

The difficulty for demand-side instruments, and particularly the use of public sector procurement to stimulate local manufacturing (generically referred to as "localisation"), is the lack of alignment between the goals of the government department which procures the product (in this case, the NDoH) and the Department of Trade and Industry which is responsible for industry promotion. Indeed, the $\mathrm{NDoH}$ has been openly and frequently critical of the BI-PPP, stating that if the Department of Trade and Industry wants local industry, it should pay for the incentivisation thereof. Similarly, if the Department of Science and Technology is seeking to build the biopharmaceuticals value chain, it should fund its ongoing support. Although Government is generally considered as a single actor within innovation systems, it is in fact a punctualised or disaggregated set of actors, each with their own mandates and objectives. The allocation of budgets to funding priorities is clearly a contested arena and can result in policy confusion or incoherence.

This study has confirmed such mixed perceptions about the value-for-money or cost-benefit ratio of the BI-PPP. In the absence of the PPP, the vaccine value chain (from R\&D to manufacture to distribution) in South Africa would undoubtedly have disappeared in its entirety. As of 2003, procurement itself was in jeopardy and the BI-PPP has fulfilled an invaluable function is ensuring security of supply since 2003. However, the cost of the initiative has been carried mostly by the $\mathrm{NDoH}$, whose priority is low-cost public health, and particularly the use of affordable vaccines as a means of addressing key challenges in public health. In this sense, $\mathrm{Bl}$ is considered to be an unnecessary burden on public health expenditure and the NDoH argued that the budgetary responsibility for vaccine localisation should, at the outset, have been allocated to the Department of Trade and Industry or the Department of Science and Technology. 
This perspective focuses too narrowly on the benefits of the PPP, which included not only skills development, technology transfer and localisation, but also the maintenance of a reliable and efficient supply chain. As already noted, BI has been successful in negotiating competitive prices for the full spectrum of vaccines, especially towards the end of the evaluation period, and ensuring that the public health depots receive the required doses. The value of this contribution was considered by stakeholders in the sector as immeasurable considering the potential disaster arising from any interruption in supply, particularly with regards to the EPI components.

Notwithstanding the debates about the budgetary responsibility, it is still important to consider the cost to treasury as a whole and the benefits to the South African economy. The former has been separated into the additional procurement cost relative to $\mathrm{PAHO}$ prices, which amounted to about R1.59 billion over the period 2010-2014, and the cost of Bl's operations/capital expenditure, which amounted to R1.14 billion over the period 2004-2015. The latter has been benchmarked against an estimated cost based on the services provided per vaccine and the associated cost of these services. Although actual or specific industry values are not available, it has been shown that the overall cost of BI's services was $20 \%$ less than the benchmark values.

A major, and ongoing, concern for the institute, however, is its limited progress towards local filling and manufacture of antigen. An important barrier to this achievement has been the nature of the PPP agreements, which have resulted in insufficient funding to finance the required capital expenditure (the premium has been sufficient to cover only the operational costs), whilst also restricting the ability of the private sector partner to raise either loan or equity capital. The latter is an important learning point for PPPs of this type and arises as a consequence of the shortterm duration of the main contracts. The supply agreement, for instance, was initially in place for only five years, and although it has since been extended for a second period, the insecurity of this contract prevented $\mathrm{Bl}$ from raising private funding to support the establishment of local manufacturing facilities.

As a consequence, the institute has followed a cautious and stagewise strategy to its skills development and capital investment programme, beginning with local repackaging/labelling only, and then backwards integrating into filling, formulating and hopefully antigen manufacture. This strategy has been necessitated by the financial and human resource constraints, both of which were largely underestimated in 2003, when the PPP was being conceptualised. The degree of deterioration of the NDoH facilities at this time, and the level of effort required to upgrade these sites to world-class centres, was not apparent to the PPP team and has resulted in the initiative failing to reach the Strategic Equity Partner undertakings.

\section{Conclusions}

Over the period 2010-2014, BI has successfully procured and distributed vaccines and has received an income of R764 million, equivalent to an average cost premium of $12 \%$, as per the terms of its Supply Agreement with the NDoH. Moreover, it has become increasingly able to supply vaccines to the public health system at globally competitive prices and has undertaken local R\&D, the latter in one case leading to a novel conjugate vaccine which has been licensed to two international companies and for which the institute is receiving royalty revenue.

All of the premium has been used to finance Bl's operational expenses and there have been insufficient retained earnings with which to build world-class local manufacturing facilities. As a result, the institute has been required to raise this capital through loans and grants. Unfortunately, these efforts have been hindered by the short-term nature of the supply agreement, which have prevented the entry of equity partners or other investors to any significant extent. This aspect of the PPP has led BI to adopt a slow and stage-wise investment strategy, beginning with repackaging/labelling and only gradually migrating upstream to more value-adding activities.

In summary, the quantitative and qualitative approaches of this study have concluded that a positive cost-benefit or value-formoney outcome has been achieved by the institute over the evaluation period. Beneficial outcomes include a capability to negotiate internationally competitive prices, an integrated distribution network, uninterrupted vaccine supply, technology transfer, skills development, a successful R\&D product and the infrastructure for local manufacture. Although it is beyond the scope of this study to comment on the future management of the PPP, it is concluded that although more could have been achieved, the results to date indicate that the initiative has acted in the interests of the public, particularly in ensuring value-formoney from the expenditure of public funds.

\section{Acknowledgements}

It is acknowledged that this article draws substantially on a previous publication (Walwyn DR, Nkolele AT. An evaluation of South Africa's public-private partnership for the localisation of vaccine research, manufacture and distribution. Health Research Policy and Systems. 2018;16(1):30). However, the content has been adapted for a South African reader and expanded to include the policy analysis.

\section{References}

1. Bustreo, F. Embrace the facts about vaccines, not the myths. 2017 [accessed 18 May 2017]. Available at: http://www.who.int/mediacentre/commentaries/2017/ embrace-facts-vaccines/en/

2. Ozawa $S$, Clark S, Portnoy A, et al. Return on investment from childhood immunization in low-and middle-income countries, 2011-20. Health Affairs. 2016;35:199-207.

3. World Health Organisation. Global Vaccine Action Plan. 2018 [accessed 23 June 2018]. Available at: www.who.int/immunization/global_vaccine_action_plan

4. Kahn T. Motsoaledi hails vaccines and bewails lack of interest in department's successes. 2015 [accessed 28 June 2018]. Available at: http://www.bdlive.co.za/ national/health/2015/05/05/motsoaledi-hails-vaccines-and-bewails-lack-ofinterest-in-departments-successes

5. Walwyn DR, Nkolele AT. An evaluation of South Africa's public-private partnership for the localisation of vaccine research, manufacture and distribution. Health Res Policy Sy. 2018;16:30. 
6. Myoken, Y. Demand-orientated policy on leading-edge industry and technology: Public procurement for innovation. International Journal of Technology Management. 2010;49:196-219.

7. Organisation for Economic Co-operation and Development. Demand-side Innovation Policies. 2011. doi: 10.1787/9789264098886-en

8. Bolton P. Public procurement as a tool to drive innovation in South Africa. PER: Potchefstroomse Elektroniese Regsblad. 2016;19:1-35.

9. African Union Commission. Pharmaceutical manufacturing plan for Africa. 2007. Addis Ababa: African Union.

10. Brinkerhoff DW, Brinkerhoff JM. Public-private partnerships: perspectives on purposes, publicness, and good governance. Public Administration and Development. 2011;31:2-14.

11. $\mathrm{Ng} \mathrm{A}$, Loosemore M. Risk allocation in the private provision of public infrastructure. International Journal of Project Management. 2007;25:66-76.

12. Karim NAA. Risk allocation in public private partnership (PPP) project: a review on risk factors. International Journal of Sustainable Construction Engineering and Technology. 2011;2:8-16.

13. National Department of Health. 2014. Strategic Plan, Department of Health, 2014/15 to 2018/19. National Department of Health (Pretoria).

14. Gray A, Suleman F, Pharasi B. South Africa's National Drug Policy: 20 years and still going? South African Health Review. 2017:49-58.

15. National Treasury. Preferential Procurement Policy Framework Act (Act 5 of 2000). Government of South Africa (Pretoria), 2000.

16. Kahn T. Aspen hails decision to boost locally made medicines. 2012 [accessed 28 June 2018]. Available at: http://www.bdlive.co.za/national/health/2015/05/05/ motsoaledi-hails-vaccines-and-bewails-lack-of-interest-in-departmentssuccesses

17. Department of Trade and Industry. Designation of Industries, Sectors \& Products for Local Procurement in the Public Sector. Department of Trade and Industry (Pretoria), 2016.

18. National Treasury. Introducing Public Private Partnerships in South Africa. 2007.

19. Naidoo, A. Biologicals and Vaccines Institute of Southern Africa Final report: review of the strategic equity partnership and recommendations on the way forward. Pretoria, South Africa: Price Water House Coppers, 2010.
20. PATH and World Health Organisation. Outsourcing the vaccine supply chain and logistics system to the private sector: the Western Cape Experience in South Africa. Seattle: PATH, 2011.

21. Makhoana M. Personal communication about the Biovac PPP. Interview ed. 2014.

22. Els D, Mabane M. State Vaccine Assets - PwC Option Analysis. Johannesburg: PriceWaterhouse Coopers, 2001.

23. Ozawa S, Pongpirul K. 10 best resources on mixed methods research in health systems. Health Policy and Planning. 2014;29:323-7.

24. Walker DG, Hutubessy R, Beutels P. WHO Guide for standardisation of economic evaluations of immunization programmes. Vaccine. 2010;28:2356-9. doi: 10.1016/j.vaccine.2009.06.035

25. WHO and IVR. WHO guide for standardisation of economic evaluation of immunisation programs. Geneva, Switzerland, 2008. Available at: www.who.int/ vaccines-documents/.

26. Srivastava A, Thomson SB. Framework analysis: a qualitative methodology for applied policy research. 2009.

27. Ritchie J, Lewis J, Nicholls CM, et al. Qualitative research practice: A guide for social science students and researchers. Sage, 2013.

28. Page C, Meyer D. Applied Research Design for Business and Management. New South Wales, Australia: McGraw-Hill, 1999.

29. Blecher MS, Meheus F, Kollipara A, et al. Financing vaccinations; the South African experience. Vaccine. 2012;30(Suppl 3):C79-C86. doi: http://dx.doi. org/10.1016/j.vaccine.2012.04.042

30. WHO. Measuring medicine prices, availability, affordability and price components. Geneva, Switzerland: World Health Organisation, 2008.

31. MSF. The right shot: bringing down barriers to affordable and adapted vaccines. Geneva: Medecins Sans Frontieres, 2015

32. Frost \& Sullivan. Socio-Economic Impact Analysis. Unpublished. 2016:1-25.

33. Roberts $S$. Understanding the effects of trade policy reform: the case of South Africa. South African Journal of Economics. 2000;68:270-81.

34. Naidoo S. Rebalancing innovation policy mix to improve support for South Africa's manufacturing sector. University of Pretoria, Johannesburg, 2016. 